\title{
A Study on Data Mining Course Teaching Based on Flipped Classroom
}

\author{
Tong Wang \\ Institute of Computer and Information Engineering \\ Shanghai Second Polytechnic University \\ Shanghai, 201209, China \\ zjxywt@163.com
}

\author{
Wenan Tan \\ Institute of Computer and Information Engineering \\ Shanghai Second Polytechnic University \\ Shanghai, 201209, China
}

\author{
Jianxin Xue \\ Institute of Computer and Information Engineering \\ Shanghai Second Polytechnic University \\ Shanghai, 201209, China
}

\begin{abstract}
The development of information technology in education has made a significant impact on course teaching reform in colleges, also makes college teachers faced with severe challenges. Start from the analysis of data mining course teaching present situation and the concept of the flipped classroom, how to effectively implement the flipped classroom teaching mode into the class of the data mining in colleges and universities is explored. This paper demonstrates basic principles and application and research status of flipped classroom model, and then puts forward to teaching model and constituent elements of flipped classroom model for data mining course. The results show that the designed teaching mode can enhance the efficiency and effectiveness of teaching, and plays an important role in developing their learning initiatives innovative abilities.
\end{abstract}

Keywords-Flipped classroom, Data mining, Teaching model, Self-study before class, Classroom training internalization, Afterschool sublimation.

\section{INTRODUCTION}

Data mining generally refers to the process of hiding information from a large amount of data. It is a step in knowledge discovery in database. Data mining is usually related to computer science, and it can be realized by many methods such as statistics, online analysis processing, information retrieval, machine learning, expert system and pattern recognition. Data mining contains ten algorithms: C4.5, K-means, Apriori, EM, AdaBoost, kNN, Naive Bayes, SVM, PageRank, CART.

In the actual teaching process of data mining course, for some complex knowledge, teachers need to take a long time for teaching. In this process, students may appear the phenomenon of cognitive overload, learning effect can't be guaranteed. How to solve the problem of cognitive overload? A simple way is to let the students preview the content of learning. On the class, detailed explanations are given in areas which are hard to understand. The key of this method lies in the effect whether good or not. How can get good preview effects? Some teachers share text tutorial or video tutorial before class. In fact, this leads to the focus discussion of this study-flip the classroom. In this mode, the teacher first recorded teaching video, which is released to the students for their self-study before the class. On the basis of self-study situation of the students, the teacher has been focused on teaching, and will spend more time in personalized counseling.

\section{THE RESEARCH STATUS AT HOME AND ABROAD OF FLIP THE CLASSROOM}

Flipping classroom is also known as the "inverted classroom", refers to a form of teaching which teaching students to watch the video, complete the study at home, and finishing the homework and knowledge internalization in the classroom [1]. It is an opposite way classroom model to teacher in the classroom during the day and the students go home at night doing homework [2]. Flipping classroom has the characteristics with students centered, students' autonomous learning, interaction between teachers and students, direct guidance of teachers, the absent students will not be left behind, teaching content permanently saved, all the students involved in learning and get individualized education[3]. In 2007, two chemistry teachers Jonathan Berman and Aaron Sams proposed the concept of flipping classroom in Woodland Park High School of the Colorado in United States, and adopted this mode in the teaching, found in this way teaching results achieved much better results than the traditional way [4]. New teaching model proposed by two teachers attracted more and more attention, popular in North America as well as primary and secondary education in the United States. Many teachers from around the world also use this model to teach Spanish, science, mathematics, and for elementary, junior high, high school and adult education [5]. In 2011, Jiangjin Jukui middle school in Chongqing city and fifth middle school of Haizhu district in Guangzhou city have implemented flipped classroom teaching mode and success [6].

Domestic scholars gradually increased to the research of flipping classroom. Yang and Yang introduced the US top ten "flipped classroom" cases. Zeng had discussed the 
characteristics and practice of flipped classroom, and think it is a successful example of exploration of individualized teaching [7]. Ma and Zhao have made an empirical study of the flipped classroom on university information technology public class. The classroom discussion can help the internalization of knowledge, and have the potential advantage for university information technology public class [8]. Zhang and Zhang proposed flipped classroom mode based on the concept of the game, in order to better promote flipped classroom in teaching practice. Research and Application on the flipped classroom mode nowadays mainly focus on primary and secondary education, in colleges and universities, especially less research achievements and applications for digital media professional courses. This paper demonstrates basic principles and application and research status of flipped classroom model, and then puts forward to teaching model and constituent elements of flipped classroom model for data mining course. The results show that the designed teaching mode can enhance the efficiency and effectiveness of teaching, and plays an important role in developing their learning initiatives innovative abilities.

\section{TEACHING PROCESS OF THE FLIPPED CLASSROOM}

The design includes three stages of the implementation process, which contains self-study before class, internalization of discussions and after-school sublimation [9].

\section{A. Self-study before class}

For some simple data mining algorithms such as association rule mining of Apriori algorithm, classification algorithm of decision tree ID3 algorithm and C4.5 algorithm, KNN algorithm and clustering algorithm of K-means algorithm. Students are required to learn micro video courses, make PPT and explain the content in class. In flipped classroom, instructional videos are provided by teachers to complete the imparting of knowledge [2]. The main objective of this phase is preliminary to complete the acceptance and understanding of knowledge and skills, that is to say the students watch the prerecorded video teaching by teacher, and learn knowledge and operation skill. In the flipped classroom course teaching practice of "data mining", firstly, prepared teaching video is shared to the network hard disk; video content and practice tasks will be learned next week are arranged in class. Secondly, the students learn knowledge or skills by watching the video, and check the problems or deficiencies exist in learning by completing the task of practice activities. If you have questions, you can ask or discuss with students or teachers to resolve by talking face to face, online exchanges and other means. Finally, record the remaining Problems can't be solved temporarily after discussion, which can be submitted to the teachers through the exchange platform, so that teachers can give topics explain or organizing discuss.

\section{B. Internalization of stage}

The classroom activities are not traditional "giving and receiving doctrine", nor pay attention to the teaching activities of teaching surface "active" , but pay attention to the knowledge, skills and individual life hug, is the process of teachers and students in the interaction of internalized skills, knowledge creation. This requires teachers can according to the specific contents of the course, rational planning, careful organization, timely cited, which really make the class become students asking questions, solve problems, internalizing knowledge of the place. In the flipped classroom of "data mining" course, according to the nature of the problem of collecting and arranging under lesson, we decided to organize the "task-based practice of inquiry-based classroom" or to organize the "classroom discussion based on the issue discussion”. If the problem is operational, procedural, or can be solved by the explanation of teachers, inquiry-based classroom is organized; if the problem collected by the teacher is controversial, theoretical issues strong, and it is difficult to explain clearly through teachers by 5-10 minutes, discussing classroom activities is organized.

In the inquiry-based classroom, firstly, operational problems or difficulty point encountered by the students are explained by teacher, the operation process is demonstrated. Then, the specific practice of tasks are thrown to students, students is in dependent inquiry or collaborative learning. Teachers observe the students study progress, guide or coach at the appropriate time, and guide the students to explore the research direction and prevent the inquiry learning become a mere formality, superficial and superficial. After the inquiry, organize students to exchange achievements and self-rating (or by the teachers' summary or feedback), namely through the guiding task inquiry, to display the results, exchange and selfevaluation, deepen the understanding of knowledge, mastering skills. After the inquiry, organize students to exchange achievements and self-rating (or by the teachers' summary or feedback), namely through the guiding task inquiry, achievements, exchange and self-evaluation, deepen the understanding of knowledge, mastering skills.

To organize the classroom discussion, first of all is to explain the problem. But the nature of the problem is different; the problem here is no longer procedural or operational problems, but the difficulties of the theoretical knowledge or controversial issues. The teacher's explanation is a summary and explanation of the problem, then more discussion of the nature of the problem is thrown by the teacher through the design and processing, which caused the students to discuss, to guide the students to deeper thinking and debate for the explanation of the problem. Teachers should pay attention to guide the direction of discussion, so as not to discuss from the theme. After the discussion, the teacher is to sort and summarize the discussions and deepen students' understanding of the issues.

The organization of flipped classroom activities has a higher requirement for teachers' teaching ability. Teachers should be sensitive to realize that the confusion of the majority of students in the classroom, timely provide solutions and give guidance. In the classroom, students will ask questions or hypotheses, some question or hypothesis which teachers may has never encountered before. Therefore, teachers should not only have a solid knowledge of the discipline, broad interdisciplinary knowledge base, but also have a keen ability to think. At the same time, teachers also have a strong organizational skills and the ability to guide the classroom discussion, so as to effectively lead the class discussion. For some teachers, this is a real challenge. 


\section{After sublimation}

Through self-study before class, lesson internalized, the students have to understand and master the basic knowledge of the contents of this chapter. However, this knowledge is still inert knowledge which is isolated, separated from reality, and not a real effectiveness. To put this knowledge into their own quality, not only requires students to understand and master the knowledge, the acquisition of skills, but also the knowledge can be internalized into the unconscious "weapon" to help student to think and solve problems. This requires not only requires students to "know, know why", but also to master how to use, how to use more effectively, more artistic. Because the knowledge not just stays in the know what it is and why it is. Based on these understanding, it is able to critically learn new ideas and put them into the existing cognitive structure; it is able to contact a number of the ideas and to migrate existing knowledge to new situations, make decisions and solve problems. This not only need to practice and reflection, but also need to exercise in the actual problem. Therefore, in flipped classroom of data mining teaching practice, we aimed at each of "knowledge set" to design skills development practice task, which are arranged after classroom activities to provide training opportunities for students to solve problems in real situations. Supplemented to reflective events, it can encourage students to self-exploration and reflection, to promote the further internalization of knowledge and skills, and to expand and sublimation.

\section{FlipPed ClassRoom PROMOTION ANALYSIS FOR DATA MINING COURSE}

\section{A. Significantly enhance the efficiency and effectiveness of teaching}

By flipped classroom, fully learning before class, timely understanding of the key points and difficulties, the emergence of cognitive conflict is obvious in advance compared with the traditional way. The student is only aware of their own lack of learning; he can have a clear direction and a strong motivation to learn. In this context, not only the students' doubts are resolved, the teacher's teaching targeted richer obvious. In the traditional way of teaching, students' cognitive conflict occurred in the presentation of teachers in the process of teaching, some students may be due to cognitive conflict and affects the following content learning, the overall effect of learning can't be guaranteed.

Similarity living environment leads to some similarities of the experience background of student. And this similarity suggests that the students would have a similar difficulty in learning the curriculum. This similarity in traditional teaching situation, teachers need to spend more time with the one on one counseling. In flipped classroom mode, the teacher can collect learning difficulties and opinions exist together before teaching. Subsequent teaching can be targeted as much as possible, individualized, improve teaching efficiency and effectiveness.

\section{B. Visualization of resources to reduce the learning difficulties}

In the traditional teaching situation, the majority of resources teachers provided are static resources of text or image. The habit of reading is the traditional way of reading. In flipped classroom, instructional video recorded by teachers is basically a memoir of classroom instruction. Students feel is not inferior to the real classroom learning experience, learning has improved significantly. In addition, after class, if students want to review previously learned content, watch the video then deepened the classroom learning experience, can help students quickly recall learning content, to accelerate understanding of the content.

\section{To enhance the students' self-learning ability}

The era of digital learning provides convenient conditions for solving problems independently by student. Flipped classroom teaching mode helps students to eliminate absolute dependence on teachers in traditional situation. In the independent learning link, cognitive conflicts can be effectively solved through a search engine or a communication tool. Keep on pushing this model helps develop students' self-learning ability.

\section{SUMMARY}

Flipped classroom implements the reversion of internalization and imparting of knowledge in the traditional classroom, truly reflect the "student-centered" philosophy of education. Flipped classroom is suitable for digital media technology course teaching, the flipped classroom model of digital media technology curriculum can be divided into three phases of pre-class video learning, classroom training internalization, after-school sublimation. The results show that the designed teaching mode can enhance the efficiency and effectiveness of teaching, and plays an important role in developing their learning initiatives innovative abilities.

\section{ACKNOWLEDGMENT}

This work was supported by National Natural Science Foundation of China (Grant No.61672022, Grant No. 61502296 and Grant No.61301249), the Municipal Natural Science Foundation of Shanghai (Grant No.15ZR1417000) and The Soft Engineering of Key Subjects Construction in Shanghai Second Polytechnic University (Grant No.XXKZD1301).

\section{REFERENCES}

[1] The flipped classroom defined [EB/OL]. http://blogs.kqed.org/mindshift/2011/09/the-flipped-classroom-defined/.

[2] J. L. Zhang,Y. Wang,B. H. Zhang. Introducing a new teaching model: flipped classroom [J]. Journal of distance education,2012(4):46-51.

[3] B. Jonathan, S. Aaron. Flip your classroom: reach every student in every class every day [M]. ISTE and ASCD, 2012:13-19.

[4] B.Mendi. Reverse classroom-changing your course delivery in exchange for mastery [EB/OL]. http://blogs.cofc.edu/tlt/2010/10/20/reverseclassroom-\%E2\%80\%93-changing-your-course-delivery-in-exchangefor-mastery/, 2010-10-20. 
[5] Y.G.Zhang, Y.J.Zhang. Perspective "Flipped classroom" [J]. Information technology in primary and middle schools, 2012(3):3-5.

[6] L. Jin. The comparison and thinking of "flipped classroom" between Chinese and American [EB/OL.

Http://blog.sina.com.cn/s/blog_6b87f20601014tvs.html

[7] Z.Zeng. Characteristic and practice and problems of the inversion teaching [J]. China educational technology, 2012, 306(7):114-117.
[8] X.L.Ma, G.Q.Zhao, T. Wu. An empirical study on the influence of flipped classroom model on information technology course teaching [J]. Journal of distance education, 2013(1):79-85.

[9] T. Robert. Inverting the linear algebra classroom[EB/OL]. http://ptezi.com/cz0rbkpy6tam/inverting-the-linear-algebra-classroom

[10] Wen, Ang Swee, Zaid, Norasykin Mohd ,Harun, Jamalludin. Enhancing students ICT problem solving skills using flipped classroom model. ICEED 2016, 2016:187-192 